\title{
Negative Fluid-Attenuated Inversion Recovery- Based Intravenous Thrombolysis Using Recombinant Tissue Plasminogen Activator in Acute Stroke Patients with Unknown Onset Time
}

\author{
Junya Aoki Kazumi Kimura Kensaku Shibazaki Yuki Sakamoto \\ Department of Stroke Medicine, Kawasaki Medical School, Kurashiki, Japan
}

Key Words

Acute ischemic stroke · Unknown onset time · Fluid-attenuated inversion recovery ·

Thrombolysis

\begin{abstract}
Background: Approximately $25 \%$ of acute stroke patients were excluded from intravenous thrombolysis using recombinant tissue plasminogen activator (IV-tPA) because of unknown onset time. Recent studies have shown that patients with unknown onset time would be able to receive IV-tPA when showing no ischemia on fluid-attenuated inversion recovery (negative FLAIR). The present study evaluated the safety and feasibility of IV-tPA in patients with unknown onset time and negative FLAIR compared to those with standard IV-tPA. Methods: Stroke patients with unknown onset time were prospectively enrolled. Only patients with an occlusion of the internal carotid artery (ICA) and/or middle cerebral artery (M1 and M2) with a Diffusion-Weighted Imaging-Alberta Stroke Program Early CT Score (DWI-ASPECTS) $\geq 5$ were analyzed. IV-tPA was performed within $3 \mathrm{~h}$ from the 'first found abnormal time' if the patient showed negative FLAIR. Standard IV-tPA patients were extracted from our registry as controls after having been matched by age and occluded artery to the negative FLAIR (N-F) group. Results: Twenty patients in the N-F group and 60 in the control group were included. National Institutes of Health Stroke Scale (NIHSS) scores [median 18 (interquartile range 1320) vs. 17 (12-20), $p=0.609$ ] and DWI-ASPECTS [9 (7-9) vs. $8(5-9), p=0.213$ ] were similar between the 2 groups. ICA occlusion was seen in $35 \%, \mathrm{M} 1$ in $50 \%$, and $\mathrm{M} 2$ in $15 \%$ in both groups. None of the N-F group and 1 (2\%) of the control group experienced symptomatic
\end{abstract}


intracerebral hemorrhage $(p=1.000)$. Recanalization within $1 \mathrm{~h}$ after IV-tPA was achieved in $6(30 \%)$ patients in the N-F group and $24(40 \%)$ in the control group $(p=0.595)$. Recanalization at $24 \mathrm{~h}$ after IV-tPA was seen in $13(65 \%)$ patients in the N-F group and $43(72 \%)$ in the control group ( $p=0.584$ ). At 7 days, $8(40 \%)$ in the $\mathrm{N}-\mathrm{F}$ group and $28(47 \%)$ in the control group had a dramatic recovery (defined as a $\geq 10$-point reduction in the total NIHSS score or a score of 0 or 1$)(p=0.796)$. At 3 months, a favorable outcome (modified Rankin scale score, $0-2$ ) was seen in $47 \%$ in the N-F group and $33 \%$ in the control group $(p=0.365)$. Conclusion: IV-tPA in negative FLAIR patients with unknown onset time appears safe and feasible.

Copyright $(2013$ S. Karger AG, Basel

\section{Introduction}

The time interval from onset to treatment is vital in acute stroke treatment. For a stroke intravenous thrombolysis using recombinant tissue plasminogen activator (IV-tPA) should be performed within 3-4.5 h of onset [1,2]. Unfortunately, approximately $14-30 \%$ of acute stroke patients are excluded from IV-tPA due to an unknown time of onset [3-5]. To rescue more patients with IV-tPA, a more advanced strategy is needed for acute stroke patients with unknown onset time.

Retrospective analyses [6-9] have shown that some acute stroke patients with unknown onset time could be treated with IV-tPA when multimodal computed tomography (CT) and magnetic resonance imaging (MRI) techniques are used. Most of these approaches are based on the mismatch concept between perfusion imaging and conventional CT or MRI [7-9], which identifies the penumbra tissues that are at high risk of infarction but can be salvaged using acute stroke intervention. However, there have been few prospective studies [10,11], and perfusion imaging has the limitation that it needs contrast administration, additional radiation, and postprocessing reconstruction.

Recent studies have proven that detectability of acute stroke using the fluid-attenuated inversion recovery (FLAIR) sequence depends significantly on the time interval from onset to imaging [12-14]. Indeed, when acute stroke patients had no hyperintense signal change on FLAIR, the onset time was strongly suspected to be within $3-4.5 \mathrm{~h}[15,16]$. Thus, a negative FLAIR finding can serve as a 'brain clock' without contrast administration and postprocessing reconstruction. We have previously reported a prospective case series of negative FLAIRbased IV-tPA for stroke patients with unknown onset time [17]. The aim of the present study was to compare the safety and feasibility of IV-tPA in patients with unknown onset time and negative FLAIR and in patients treated according to the standard IV-tPA protocol.

\section{Methods}

\section{Patients}

Consecutive acute stroke patients with unknown onset time who were admitted to our stroke center and treated with IV-tPA based on a negative FLAIR between June 2009 and July 2012 were prospectively enrolled. Patients were defined as having unknown onset time when the 'last known normal time' was not consistent with the 'first found abnormal time'. The last known normal time was defined as the time when the patient was last known to be without any neurological deficit. The first found abnormal time was defined as the time when the patient or a witness first noted new neurological deficits. IV-tPA was conducted within $3 \mathrm{~h}$ from the first found abnormal time if the patients showed negative FLAIR. The assessment of negative FLAIR was performed as described previously [12]. All patients and their family 
provided a written, Institutional Review Board-approved informed consent to participate in this study. This study of IV-tPA based on negative FLAIR was registered with the Japan Clinical Trials Registry (http://umin.ac.jp/ctr/index/htm) as study No. UMIN000001808 [17]. A single alteplase dose of $0.6 \mathrm{mg} / \mathrm{kg}$ (not exceeding $60 \mathrm{mg}$ ) was administered intravenously, with $10 \%$ given as a bolus, followed by continuous infusion of the remainder over $1 \mathrm{~h}$. Inclusion criteria for IV-tPA based on negative FLAIR were: (1) presentation within 3-24 h after the last known normal time, (2) anterior circulation stroke, and (3) presence of major vessel occlusion defined as involving the internal carotid artery (ICA) and/or the horizontal (M1) or vertical (M2) portion of the middle cerebral artery (MCA) on initial magnetic resonance angiography (MRA). Patients with a malignant profile on the initial diffusion-weighted imaging (DWI) were also excluded, using a DWI-Alberta Stroke Program Early CT Score (DWIASPECTS $\leq 5$ to define a malignant profile $[18,19]$. Patients with contraindications to MRI, such as an implanted cardiac pacemaker or cranial artery clipping, were also excluded. Intraarterial intervention was not used in this study. Other inclusion and exclusion criteria besides imaging were similar to those used in the Japan Alteplase Clinical Trial [20]. Stroke patients treated with standard IV-tPA within $3 \mathrm{~h}$ of onset between October 2005 and July 2012 were extracted from our stroke registry as control subjects. Because retrospective analysis revealed that 2 of 5 patients with DWI-ASPECTS were treated with IV-tPA based on negative FLAIR and included in the data analysis, DWI-ASPECTS $\geq 5$ was defined as an inclusion criterion for the control subjects. Age and occluded artery were matched to the treated patients with negative FLAIR.

\section{MRI Protocol}

MRI was conducted using commercially available echo planar instrumentation on a 1.5-tesla unit (Signa EXCITE XL ver. 11.0; GE Healthcare, Milwaukee, Wisc., USA) with DWI, FLAIR, T2* gradient echo sequences (T2*), and MRA sequences. DWI was obtained using the following parameters: repetition time (TR), 6,000 ms; echo time (TE), $78 \mathrm{~ms}$; b values, 0 and $1,000 \mathrm{~s} / \mathrm{mm}^{2}$; field of view, $24 \mathrm{~cm}$; acquisition matrix, $128 \times 192$, and slice thickness, $6.0 \mathrm{~mm}$ with a $1.0-\mathrm{mm}$ intersection gap. FLAIR sequences were obtained in the axial plane using the following parameters: TR, 8,002 ms; TE, $109 \mathrm{~ms}$; inversion time, 2,000 ms; field of view, 24 $\mathrm{cm}$; acquisition matrix, $256 \times 224$, and section thickness, $6.0 \mathrm{~mm}$ with a $1.0-\mathrm{mm}$ intersection gap. T2* was obtained using the following parameters: TR, $700 \mathrm{~ms}$; TE, $20 \mathrm{~ms}$; field of view, $24 \mathrm{~cm}$; acquisition matrix, $256 \times 192$, and section thickness, $6.0 \mathrm{~mm}$ with a $1.0-\mathrm{mm}$ intersection gap. Time-of-flight MRA covered the circle of Willis with TR, $25 \mathrm{~ms}$; TE, $6.9 \mathrm{~ms}$, and flip angle, $20^{\circ}$.

\section{Patient Background Characteristics}

The following information about the IV-tPA patients with negative FLAIR and control subjects was obtained: age, sex, vascular risk factors, atrial fibrillation, and stroke etiology. Cardiovascular risk factors were identified as follows: (1) hypertension, a history of using antihypertensive agents, systolic blood pressure $\geq 140 \mathrm{~mm} \mathrm{Hg}$, or diastolic blood pressure $\geq 90 \mathrm{~mm} \mathrm{Hg}$ at hospital discharge, (2) diabetes mellitus, use of hypoglycemics, random glucose level $\geq 200 \mathrm{mg} / \mathrm{dl}$, or glycosylated hemoglobin $>6.4 \%$ on admission, and (3) hyperlipidemia, use of antihyperlipidemic agents, or serum cholesterol level $>220 \mathrm{mg} / \mathrm{dl}$. Stroke etiology was determined at hospital discharge using Trial of Org 10172 in Acute Stroke Treatment criteria.

\section{Recanalization and Hemorrhagic Transformation}

The presence of recanalization was assessed using MRA $1 \mathrm{~h}$ (early recanalization) and $24 \mathrm{~h}$ after IV-tPA. Recanalization was defined as partial or complete recanalization using the method reported previously [21]. Symptomatic intracerebral hemorrhage (sICH) was 
defined according to the Safe Implementation of Thrombolysis in Stroke - Monitoring Study protocol as parenchymal hemorrhage type 2 combined with an increase in the National Institutes of Health Stroke Scale (NIHSS) score of $\geq 4$ from baseline [22]. Additionally, the presence of hemorrhagic transformation (HT), determined as a new appearance of low-intensity lesions on T2* compared to initial T2* findings, was routinely evaluated 1 and $24 \mathrm{~h}$ after IV-tPA.

\section{Neurological Assessment}

Neurological deficits were assessed using the NIHSS score before and $1 \mathrm{~h}, 24 \mathrm{~h}$, and 7 days after IV-tPA. Clinical improvement or deterioration was assessed by the methods used in previous reports at $24 \mathrm{~h}$ and 7 days after onset [23]. Dramatic recovery was defined as a $\geq 10$ point reduction in the total NIHSS score or a total NIHSS score of $0-1$. Good recovery was defined as a $\geq 4$-point reduction in the total NIHSS score, excluding dramatic recovery. No change was defined as from a 3-point increase to a 3-point reduction in the total NIHSS score. Worsening was defined as a $\geq 4$-point increase in the total NIHSS sore. At 3 months after onset, clinical outcome was assessed using the modified Rankin scale (mRS) in patients eligible for follow-up. A favorable outcome was defined as an mRS score of $0-2$.

\section{Ischemic Volume Analysis}

Ischemic lesion volume was measured using NIH-image software before and 1 and $24 \mathrm{~h}$ after IV-tPA on DWI and at 7 days on FLAIR. First, the perimeter of the area of abnormal signal intensity was traced on each DWI and FLAIR image, and then the NIH-image calculated the total volume using the thickness and the area traced on the slice. The window level and window width were chosen to obtain the best contrast between the lesion and the normal surrounding tissue.

\section{Statistical Analysis}

Safety was evaluated using sICH as the outcome. Feasibility included a dramatic recovery at $24 \mathrm{~h}$ and 7 days, as well as a favorable outcome at 3 months after onset. After baseline and clinical characteristics had been compared between the IV-tPA patients and negative FLAIR (N-F group) and the control subjects (control group), safety and feasibility were compared between the 2 groups. The incidence of asymptomatic hemorrhage at 1 and $24 \mathrm{~h}$ was also compared between the 2 groups. The clinical and radiological analyses of the N-F group patients were compared based on the site of arterial occlusion. The Mann-Whitney U test was used to analyze differences in continuous variables, and Fisher's exact test was used to analyze differences in categorical variables. The data are presented as median values (interquartile range) and frequencies (percentage). All statistical analyses were performed using IBM SPSS Statistics software version 19 (Chicago, Ill., USA). Results were considered significant when $\mathrm{p}<0.05$.

\section{Results}

The subjects included 20 patients in the N-F group and 60 patients in the control group. Age [median, 83 (67-90) years vs. $82(73-85)$ years, $p=0.841]$ and sex [male, $8(40 \%)$ vs. 30 (50\%), $\mathrm{p}=0.606$ ] did not differ between the 2 groups. The initial NIHSS score was $18(13-20)$ in the N-F group and $17(12-20)$ in the control group $(p=0.609)$. The median interval between the last known normal time and IV-tPA was significantly longer in the N-F group than in the control group [5.6 (4.2-12.2) h vs. $2.4(2.0-2.7) \mathrm{h}, \mathrm{p}<0.001]$. The frequencies of major artery occlusions were identical between the 2 groups: ICA 35\%, M1 50\%, and M2 15\% ( $p=1.000)$. 
Aoki et al.: Thrombolysis for Patients with Unknown Onset Time

Table 1. Clinical characteristics and imaging findings in the N-F group and the control group

\begin{tabular}{|c|c|c|c|}
\hline Variables & $\begin{array}{l}\text { N-F group } \\
(\mathrm{n}=20)\end{array}$ & $\begin{array}{l}\text { Control group } \\
(n=60)\end{array}$ & $\mathrm{p}$ \\
\hline Age, years & $83(67-90)$ & $82(73-85)$ & 0.841 \\
\hline Male sex & $8(40)$ & $30(50)$ & 0.606 \\
\hline NIHSS on admission & $18(13-20)$ & $17(12-20)$ & 0.609 \\
\hline $\mathrm{mRS} 0-2$ & $15(75)$ & $46(77)$ & 1.000 \\
\hline Interval from onset to IV-tPA, h & $5.6(4.2-12.2)$ & $2.4(2.0-2.7)$ & $<0.001$ \\
\hline Initial DWI-ASPECTS & $9(7-9)$ & $8(5-9)$ & 0.213 \\
\hline Initial ischemic volume on DWI, ml & $5.3(2.6-27.3)$ & $8.1(1.2-33.9)$ & 0.807 \\
\hline \multicolumn{4}{|l|}{ Past history } \\
\hline Ischemic stroke & $0(0)$ & $8(13)$ & 0.191 \\
\hline Transient ischemic attack & $2(10)$ & $3(5)$ & 0.594 \\
\hline Coronary heart disease & $3(15)$ & $5(8)$ & 0.405 \\
\hline \multicolumn{4}{|l|}{ Vascular risk factor } \\
\hline Hypertension & $18(90)$ & $46(77)$ & 0.333 \\
\hline Diabetes mellitus & $6(30)$ & $15(25)$ & 0.770 \\
\hline Hyperlipidemia & $7(35)$ & $18(30)$ & 0.782 \\
\hline Smoking & $6(30)$ & $21(35)$ & 0.789 \\
\hline Atrial fibrillation & $14(70)$ & $36(60)$ & 0.595 \\
\hline \multicolumn{4}{|l|}{ Past medication } \\
\hline Antiplatelet therapy & $6(30)$ & $15(25)$ & 0.770 \\
\hline Anticoagulation therapy & $1(5)$ & $10(17)$ & 0.275 \\
\hline Systolic blood pressure, mm Hg & $151(140-165)$ & $154(138-166)$ & 0.770 \\
\hline Diastolic blood pressure, $\mathrm{mm} \mathrm{Hg}$ & $80(71-101)$ & $82(68-98)$ & 0.634 \\
\hline \multicolumn{4}{|l|}{ Stroke etiology } \\
\hline Cardioembolism & $16(80)$ & $38(63)$ & 0.270 \\
\hline Large-artery atherosclerosis & $1(5)$ & $6(10)$ & 0.673 \\
\hline \multicolumn{4}{|l|}{ Laboratory data } \\
\hline White blood cell count, /l & $6,555(5,093-7,725)$ & $6,135(4,943-7,743)$ & 0.837 \\
\hline Red blood cell count & $407(375-4,456)$ & $408(361-442)$ & 0.697 \\
\hline Hemoglobin, mg/dl & $12.6(11.7-13.7)$ & $12.4(11.2-13.8)$ & 0.859 \\
\hline Platelets & $21.0(16.5-24.2)$ & $18.6(15.4-21.5)$ & 0.085 \\
\hline Total cholesterol, mg/dl & $191(163-216)$ & $181(159-209)$ & 0.501 \\
\hline $\mathrm{LDL}, \mathrm{mg} / \mathrm{dl}$ & $106(86-131)$ & $107(85-134)$ & 0.947 \\
\hline D-dimer, $\mu \mathrm{g} / \mathrm{ml}$ & $2.2(1.0-3.8)$ & $1.4(0.6-2.9)$ & 0.139 \\
\hline Glucose, mg/dl & $118(103-166)$ & $133(113-164)$ & 0.182 \\
\hline $\mathrm{HbA1c} \%$ & $5.7(5.3-6.6)$ & $5.6(5.2-5.9)$ & 0.483 \\
\hline CRP, mg/dl & $0.13(0.09-0.67)$ & $0.12(0.04-0.50)$ & 0.344 \\
\hline BNP, pg/ml & $223.4(80.9-440.8)$ & $135.6(72.3-329.7)$ & 0.417 \\
\hline \multicolumn{4}{|l|}{ Site of occlusion } \\
\hline ICA & $7(35)$ & $21(35)$ & 1.000 \\
\hline Horizontal portion of MCA & $10(50)$ & $30(50)$ & 1.000 \\
\hline Vertical portion of MCA & $3(15)$ & $9(15)$ & 1.000 \\
\hline
\end{tabular}

Values represent median with the interquartile range in parentheses or number with the percentage in parentheses. $\mathrm{LDL}=$ Low-density lipoprotein cholesterol; HbA1c = hemoglobin A1c; CRP = C-reactive protein; $\mathrm{BNP}=$ brain natriuretic peptide.

DWI-ASPECTS before IV-tPA was 9 (7-9) in the N-F group and 8 (5-9) in the control group ( $\mathrm{p}=0.213$ ). Other baseline characteristics are shown in table 1.

Regarding safety, only 1 (2\%) patient in the control group developed sICH $1 \mathrm{~h}$ after IV-tPA, and none in the N-F group had sICH ( $p=1.000$, table 2$)$. The incidence of HT was also similar between the 2 groups. At $1 \mathrm{~h}$ after IV-tPA, 1 (5\%) of the 20 patients in the N-F group 
Aoki et al.: Thrombolysis for Patients with Unknown Onset Time

Table 2. Short-term radiological outcomes in the N-F group and the control group

\begin{tabular}{|c|c|c|c|}
\hline Variables & $\begin{array}{l}\text { N-F group } \\
(\mathrm{n}=20)\end{array}$ & $\begin{array}{l}\text { Control group } \\
(\mathrm{n}=60)\end{array}$ & $\mathrm{p}$ \\
\hline sICH & $0(0)$ & $1(2)$ & 1.000 \\
\hline \multicolumn{4}{|l|}{ Hemorrhagic transformation } \\
\hline $1 \mathrm{~h}$ & $1(5)$ & $4(7)$ & 1.000 \\
\hline Parenchymal hematoma type 2 & $0(0)$ & $3 / 4(75)$ & 0.400 \\
\hline $24 \mathrm{~h}$ & $8(40)$ & $24(40)$ & 1.000 \\
\hline Parenchymal hematoma type 2 & $0(0)$ & $6 / 24(25)$ & 0.296 \\
\hline \multicolumn{4}{|l|}{ Recanalization } \\
\hline $1 \mathrm{~h}$ & $6(30)$ & $24(40)$ & 0.595 \\
\hline Complete & 1 & 6 & \\
\hline Partial & 5 & 18 & \\
\hline $24 \mathrm{~h}$ & $13(65)$ & $43(72)$ & 0.584 \\
\hline Complete & 7 & 22 & \\
\hline Partial & 6 & 21 & \\
\hline \multicolumn{4}{|l|}{ Serial ischemic volume, $\mathrm{ml}$} \\
\hline $1 \mathrm{~h}$ & $10.5(3.3-41.7)$ & $13.8(4.9-48.0)$ & 0.505 \\
\hline $24 \mathrm{~h}^{\mathrm{a}}$ & $21.8(8.7-66.7)$ & $35.6(9.3-105.7)$ & 0.404 \\
\hline 7 days $s^{b}$ & $50.1(10.7-141.7)$ & $50.0(12.7-136.0)$ & 0.701 \\
\hline
\end{tabular}

Values represent number with the percentage in parentheses or median with the interquartile range in parentheses. ${ }^{\text {a }} 1$ patient was not evaluated with MRI $24 \mathrm{~h}$ after thrombolysis. ${ }^{\mathrm{b}} 3$ patients were not evaluated with MRI 7 days after thrombolysis.

and $4(7 \%)$ of the 60 patients in the control group had HT ( $\mathrm{p}=1.000)$. At $24 \mathrm{~h}$ after IV-tPA, 8 $(40 \%)$ in the N-F group and $24(40 \%)$ in the control group had HT ( $=1.000)$. However, none of the patients in the N-F group had parenchymal hemorrhage type 2.

The rates of early recanalization and recanalization at $24 \mathrm{~h}$ after IV-tPA were 30 and $65 \%$, respectively, in the N-F group and 40 and $72 \%$, respectively, in the control group ( $p=0.595$ and 0.584 , respectively). The rates of complete and partial recanalization were not different between the 2 groups. Serial ischemic volumes on DWI and FLAIR were also not different between the 2 groups.

Concerning clinical improvement, a dramatic recovery at $24 \mathrm{~h}$ was seen in 4 (20\%) patients in the N-F group and $13(22 \%)$ patients in the control group ( $\mathrm{p}=1.000)$. At 7 days, 8 $(40 \%)$ in the N-F group and $28(47 \%)$ in the control group had a dramatic recovery $(\mathrm{p}=$ 0.796 ). The rates of worsening were also similar between the 2 groups both at $24 \mathrm{~h}$ and 7 days after IV-tPA ( $\mathrm{p}=1.000$ and 0.722 , respectively; fig. 1 ).

Figure 2 presents the clinical outcome 3 months after stroke onset for the 61 patients with premorbid mRS scores of $0-2$. The rate of a favorable outcome was not different between the N-F group and the control group; 7 (47\%) of 15 patients in the N-F group and 15 (33\%) of 46 patients in the control group had a favorable outcome $(p=0.365)$.

Finally, the clinical and radiological outcomes were evaluated based on the arterial occlusion site in the N-F group (table 3 ). Of the 7 patients with ICA occlusion, none $(0 \%)$ had complete recanalization. On the other hand, 7 (54\%) with MCA occlusion had complete recanalization at $24 \mathrm{~h}(\mathrm{p}=0.044)$. Ischemic volume at 7 days was larger in patients with ICA occlusion than in those with MCA occlusion ( $p=0.097)$. Clinical outcome also showed similar tendencies. None of the 4 patients with ICA occlusion with a premorbid mRS score of $0-2$ and 7 of the 11 with MCA occlusion had a favorable outcome at 3 months ( $p=0.077$ ). 


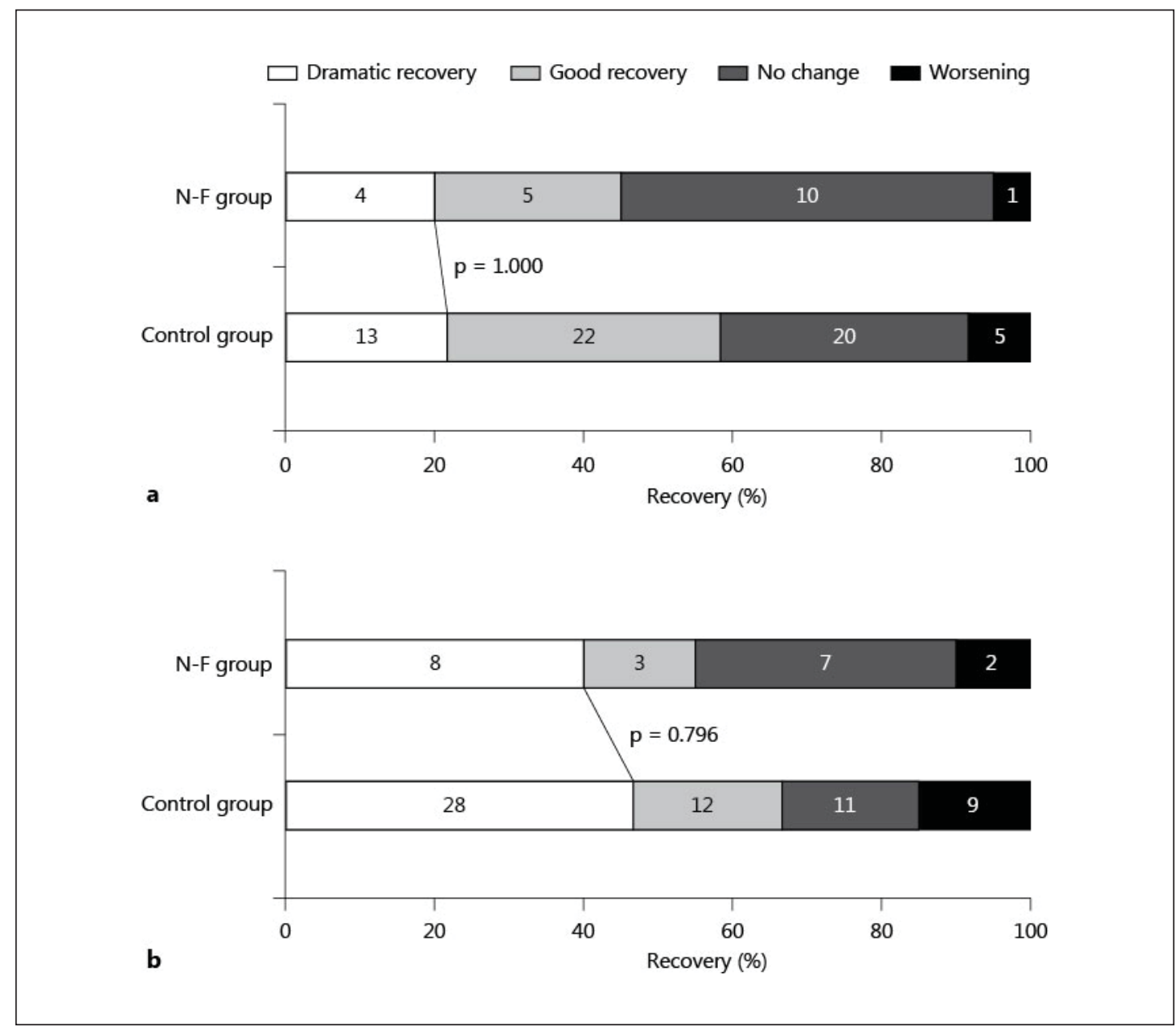

Fig. 1. Short-term neurological recovery at $24 \mathrm{~h}$ (a) and 7 days (b) after intravenous thrombolysis in the N-F group and the control group. Numbers of patients are presented in the bars.

\section{Discussion}

The current study had two major findings: (1) IV-tPA based on negative FLAIR is a safe and feasible treatment, and (2) the benefit of IV-tPA for patients with ICA occlusion was limited.

The sICH rate was not higher in negative FLAIR-based IV-tPA for stroke patients with unknown onset time than in standard IV-tPA. The clinical outcome at 3 months, as well as short-term neurological recovery, was not different between the IV-tPA patients with negative FLAIR and the control group. Furthermore, quantitative analysis revealed similar ischemic volumes at $1 \mathrm{~h}, 24 \mathrm{~h}$, and 7 days after IV-tPA between the 2 groups. To the best of our knowledge, this is the first prospective study that compared the safety and feasibility of IV-tPA for negative FLAIR patients to standard IV-tPA. Previously, FLAIR signal change has been related to the time interval from onset to imaging [12]. Recent reports have shown that negative FLAIR can predict the time of stroke onset as within $3-4.5 \mathrm{~h}[15,16]$. This predictive time frame matches the time window for IV-tPA exactly. This ability of negative FLAIR mismatch to act as a 'brain clock' was likely responsible for the present findings. IV-tPA can be considered when acute stroke patients with unknown onset time are proven to have negative FLAIR. 


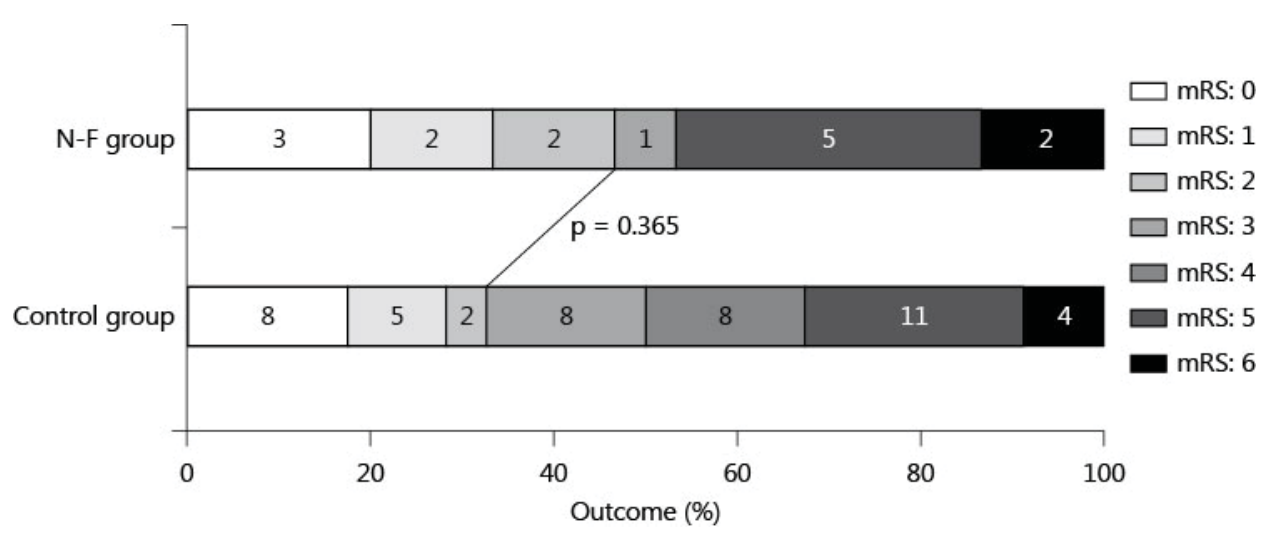

Fig. 2. mRS score at 3 months after onset of 61 patients with a premorbid mRS score of $0-2$. Numbers of patients are presented in the bars.

Table 3. Clinical and radiological outcomes of negative FLAIR patients with MCA occlusion and ICA occlusion

\begin{tabular}{|c|c|c|c|}
\hline Variables & $\begin{array}{l}\text { MCA occlusion } \\
(\mathrm{n}=13)\end{array}$ & $\begin{array}{l}\text { ICA occlusion } \\
(n=7)\end{array}$ & $\mathrm{p}$ \\
\hline \multicolumn{4}{|l|}{ Clinical outcome } \\
\hline \multicolumn{4}{|l|}{ Dramatic recovery } \\
\hline $24 \mathrm{~h}$ & $4 / 13(31)$ & $0 / 7(0)$ & 0.249 \\
\hline 7 days & $7 / 13(54)$ & $1 / 7(14)$ & 0.158 \\
\hline Favorable outcome at 3 months & $7 / 11(64)$ & $0 / 4(0)$ & 0.077 \\
\hline \multicolumn{4}{|l|}{ Serial ischemic volume, $\mathrm{ml}$} \\
\hline Initial & $4.9(2.3-29.1)$ & $9.0(2.9-22.3)$ & 0.877 \\
\hline $1 \mathrm{~h}$ & $11.5(2.7-39.2)$ & $9.4(3.8-51.7)$ & 0.817 \\
\hline $24 \mathrm{~h}$ & $13.8(5.7-56.3)$ & $29.8(8.7-281.6)$ & 0.211 \\
\hline 7 days & $50.1(6.5-70.2)$ & $138.6(31.7-300.8)$ & 0.097 \\
\hline \multicolumn{4}{|l|}{ Recanalization } \\
\hline $1 \mathrm{~h}$ & $5(39)$ & $1(14)$ & 0.354 \\
\hline Complete & 1 & 0 & \\
\hline Partial & 4 & 1 & \\
\hline $24 \mathrm{~h}$ & $10(77)$ & $3(43)$ & 0.174 \\
\hline Complete & 7 & 0 & \\
\hline Partial & 3 & 3 & \\
\hline
\end{tabular}

Values represent number with the percentage in parentheses or median with the interquartile range in parentheses.

In the present study, the rate of complete recanalization at $24 \mathrm{~h}$ was significantly lower in patients with ICA occlusion than in those with MCA occlusion. None of the patients with ICA occlusion had a favorable outcome at 3 months. Previous studies have demonstrated a similar low rate of recanalization in patients with ICA occlusion [24, 25]. It was also found that ICA occlusion was a significant predictor of poor outcome within 3-6 h of onset [26, 27]. Large 
vessel occlusion derives from a large embolus resistant to thrombolysis using IV-tPA and prevents the collateral flow pathway, especially when the thrombus occludes the ICA at the terminal portion. A recent meta-analysis demonstrated the utility of intra-arterial treatment for acute ICA occlusion [28]. We have previously demonstrated that the administration of a free radical scavenger may increase the rate of recanalization [29]. An immediate combination of these treatments should be considered in acute stroke patients with ICA occlusion and unknown onset time.

The Reperfusion Therapy in Unclear-Onset Stroke Based on MRI Evaluation (RESTORE) study showed similar findings [11]. The RESTORE study treated 83 patients with unknown onset time and concluded that MRI-based reperfusion therapy was feasible and safe. They used perfusion-DWI mismatch criteria as well as FLAIR criteria. FLAIR criteria include patients with negative FLAIR, as well as those with subtle FLAIR change who were excluded from the present study. Patients without occlusion were also included. Regarding intervention, the most commonly administered treatment was intra-arterial therapy alone in 57 (69\%) patients, while IV-tPA alone was used in only 9 (11\%). Although there are the abovementioned differences, both the RESTORE study and the present study showed that that MRIbased intervention is a promising treatment for acute stroke with unknown onset time.

Although many epidemiological studies have been published, there are no confirmed data on the clinical and radiological characteristics of patients with unknown onset time. While there are reports discussing the severe neurological deficits in patients with wake-up stroke $[4,30]$, another report showed that wake-up stroke patients only rarely had a severe type of stroke compared to patients with known onset time [5]. Regarding radiological findings, the rates of early ischemic change on CT and MRI including DWI and perfusion sequences were reported as similar between the patients with wake-up stroke and those with known onset time [3, 31,32]. On the other hand, a prospective study showed that an ischemic lesion seen on initial CT was observed $10 \%$ more frequently in patients with wake-up stroke than in other strokes [10]. The apparent diffusion coefficient value was lower in wake-up stroke in an MRI study [3]. A variety of reasons for unknown onset time may result in different patients' characteristics. Although the RESTORE study found no difference between patients with wake-up stroke and unwitnessed stroke [11], another study reported that stroke patients with unwitnessed stroke had higher NIHSS scores [33]. Ischemic change on early CT was frequently seen in patients with unwitnessed stroke [34]. In the present study, both clinical features and ischemic volumes on early DWI in IV-tPA patients with negative FLAIR were similar to those in patients with standard criteria. The present study cohort consisted of stroke patients with wake-up onset, as well as those lacking a witness. In addition, all patients had major artery occlusion that has a high likelihood of resulting in severe neurological damage without acute stroke intervention. Therefore, we considered that our negative FLAIR criteria have enough utility in clinical practice to identify the candidates for IV-tPA among patients with unknown onset time of stroke, especially those with major arterial occlusion.

There are several limitations that must be considered in the present study. First, the number of enrolled patients was small. Second, a $0.6 \mathrm{mg} / \mathrm{kg}$ dose of t-PA was used based on the Japanese guidelines. If the internationally recommended dose had been used instead, the rates of early recanalization and sICH may have been different. Third, posterior circulation stroke was excluded. Fourth, patients without occlusion before IV-tPA and those with large ischemic volume on early DWI were also excluded. Fifth, the 2 groups were not entirely comparable. Patients in the N-F group were admitted from 2009 to 2012, whereas control patients were admitted from 2005 to 2012 . With improvement in stroke management, it has been shown that the prognosis of stroke patients is generally getting better. In addition, the negative FLAIR concept is not established. Indeed, there are conflicting data that FLAIR signal change is not associated with the radiological and clinical courses after IV-tPA $[35,36]$ and 
does not estimate the onset time [36]. Finally, negative FLAIR is a subjective index. Using some software and $\mathrm{T} 2$ values with a strong magnetic field may be more useful to estimate the onset time [37, 38]. Further large, prospective, randomized trials are recommended to elucidate these issues.

In conclusion, the present study showed that IV-tPA based on negative FLAIR appears to be safe and feasible compared to standard IV-tPA.

\section{Disclosure Statement}

The authors have no conflicts of interest or funding sources to disclose.

\section{References}

$>1$ Tissue plasminogen activator for acute ischemic stroke. The National Institute of Neurological Disorders and Stroke rt-PA Stroke Study Group. N Engl J Med 1995;333:1581-1587.

-2 Hacke W, Kaste M, Bluhmki E, Brozman M, Davalos A, Guidetti D, Larrue V, Lees KR, Medeghri Z, Machnig T, Schneider D, von Kummer R, Wahlgren N, Toni D: Thrombolysis with alteplase 3 to $4.5 \mathrm{~h}$ after acute ischemic stroke. N Engl J Med 2008;359:1317-1329.

- 3 Fink JN, Kumar S, Horkan C, Linfante I, Selim MH, Caplan LR, Schlaug G: The stroke patient who woke up: clinical and radiological features, including diffusion and perfusion MRI. Stroke 2002;33:988-993.

4 Mackey J, Kleindorfer D, Sucharew H, Moomaw CJ, Kissela BM, Alwell K, Flaherty ML, Woo D, Khatri P, Adeoye O, Ferioli S, Khoury JC, Hornung R, Broderick JP: Population-based study of wake-up strokes. Neurology 2011; 76:1662-1667.

5 Moradiya Y, Janjua N: Presentation and outcomes of 'wake-up strokes' in a large randomized stroke trial: analysis of data from the International Stroke Trial. J Stroke Cerebrovasc Dis 2012, E-pub ahead of print.

6 6 Barreto AD, Martin-Schild S, Hallevi H, Morales MM, Abraham AT, Gonzales NR, Illoh K, Grotta JC, Savitz SI: Thrombolytic therapy for patients who wake-up with stroke. Stroke 2009;40:827-832.

7 Cho AH, Sohn SI, Han MK, Lee DH, Kim JS, Choi CG, Sohn CH, Kwon SU, Suh DC, Kim SJ, Bae HJ, Kang DW: Safety and efficacy of MRI-based thrombolysis in unclear-onset stroke. A preliminary report. Cerebrovasc Dis 2008; 25:572-579.

-8 Breuer L, Schellinger PD, Huttner HB, Halwachs R, Engelhorn T, Doerfler A, Kohrmann M: Feasibility and safety of magnetic resonance imaging-based thrombolysis in patients with stroke on awakening: initial single-centre experience. Int J Stroke 2010;5:68-73.

-9 Kim JT, Park MS, Nam TS, Choi SM, Kim BC, Kim MK, Cho KH: Thrombolysis as a factor associated with favorable outcomes in patients with unclear-onset stroke. Eur J Neurol 2011;18:988-994.

10 Adams HP Jr, Leira EC, Torner JC, Barnathan E, Padgett L, Effron MB, Hacke W: Treating patients with 'wake-up' stroke: the experience of the AbESTT-II trial. Stroke 2008;39:3277-3282.

-11 Kang DW, Sohn SI, Hong KS, Yu KH, Hwang YH, Han MK, Lee J, Park JM, Cho AH, Kim HJ, Kim DE, Cho YJ, Koo J, Yun SC, Kwon SU, Bae HJ, Kim JS: Reperfusion therapy in unclear-onset stroke based on MRI evaluation (RESTORE): a prospective multicenter study. Stroke 2012;43:3278-3283.

12 Aoki J, Kimura K, Iguchi Y, Shibazaki K, Sakai K, Iwanaga T: FLAIR can estimate the onset time in acute ischemic stroke patients. J Neurol Sci 2010;293:39-44.

13 Perkins CJ, Kahya E, Roque CT, Roche PE, Newman GC: Fluid-attenuated inversion recovery and diffusion- and perfusion-weighted MRI abnormalities in 117 consecutive patients with stroke symptoms. Stroke 2001;32: 2774-2781.

14 Noguchi K, Ogawa T, Inugami A, Fujita H, Hatazawa J, Shimosegawa E, Okudera T, Uemura K, Seto H: MRI of acute cerebral infarction: a comparison of FLAIR and T2-weighted fast spin-echo imaging. Neuroradiology 1997;39:406-410.

15 Thomalla G, Rossbach P, Rosenkranz M, Siemonsen S, Krutzelmann A, Fiehler J, Gerloff C: Negative fluid-attenuated inversion recovery imaging identifies acute ischemic stroke at 3 h or less. Ann Neurol 2009;65:724-732.

16 Thomalla G, Cheng B, Ebinger M, Hao Q, Tourdias T, Wu O, Kim JS, Breuer L, Singer OC, Warach S, Christensen S, Treszl A, Forkert ND, Galinovic I, Rosenkranz M, Engelhorn T, Kohrmann M, Endres M, Kang DW, Dousset V, Sorensen AG, Liebeskind DS, Fiebach JB, Fiehler J, Gerloff C: DWI-FLAIR mismatch for the identification of patients with acute ischaemic stroke within $4.5 \mathrm{~h}$ of symptom onset (PRE-FLAIR): a multicentre observational study. Lancet Neurol 2011;10:978-986.

-17 Aoki J, Kimura K, Iguchi Y, Shibazaki K, Iwanaga T, Watanabe M, Kobayashi K, Sakai K, Sakamoto Y: Intravenous thrombolysis based on diffusion-weighted imaging and fluid-attenuated inversion recovery mismatch in acute stroke patients with unknown onset time. Cerebrovasc Dis 2011;31:435-441. 
Aoki et al.: Thrombolysis for Patients with Unknown Onset Time

18 Kimura K, Iguchi Y, Shibazaki K, Terasawa Y, Inoue T, Uemura J, Aoki J: Large ischemic lesions on diffusionweighted imaging done before intravenous tissue plasminogen activator thrombolysis predicts a poor outcome in patients with acute stroke. Stroke 2008;39:2388-2391.

$>19$ Nezu T, Koga M, Kimura K, Shiokawa Y, Nakagawara J, Furui E, Yamagami H, Okada Y, Hasegawa Y, Kario K, Okuda S, Nishiyama K, Naganuma M, Minematsu K, Toyoda K: Pretreatment ASPECTS on DWI predicts 3-month outcome following rt-PA: SAMURAI rt-PA Registry. Neurology 2010;75:555-561.

20 Yamaguchi T, Mori E, Minematsu K, Nakagawara J, Hashi K, Saito I, Shinohara Y: Alteplase at $0.6 \mathrm{mg} / \mathrm{kg}$ for acute ischemic stroke within 3 h of onset: Japan Alteplase Clinical Trial (J-ACT). Stroke 2006;37:1810-1815.

-21 Kimura K, Iguchi Y, Shibazaki K, Watanabe M, Iwanaga T, Aoki J: M1 susceptibility vessel sign on T2* as a strong predictor for no early recanalization after IV-t-PA in acute ischemic stroke. Stroke 2009;40:3130-3132.

-22 Wahlgren N, Ahmed N, Davalos A, Ford GA, Grond M, Hacke W, Hennerici MG, Kaste M, Kuelkens S, Larrue V, Lees KR, Roine RO, Soinne L, Toni D, Vanhooren G: Thrombolysis with alteplase for acute ischaemic stroke in the Safe Implementation of Thrombolysis in Stroke-Monitoring Study (SITS-MOST): an observational study. Lancet 2007;369:275-282.

23 Kimura K, Iguchi Y, Shibazaki K, Iwanaga T, Yamashita S, Aoki J: IV t-PA therapy in acute stroke patients with atrial fibrillation. J Neurol Sci 2009;276:6-8.

24 Lee KY, Han SW, Kim SH, Nam HS, Ahn SW, Kim DJ, Seo SH, Kim DI, Heo JH: Early recanalization after intravenous administration of recombinant tissue plasminogen activator as assessed by pre- and post-thrombolytic angiography in acute ischemic stroke patients. Stroke 2007;38:192-193.

-25 Saqqur M, Uchino K, Demchuk AM, Molina CA, Garami Z, Calleja S, Akhtar N, Orouk FO, Salam A, Shuaib A, Alexandrov AV: Site of arterial occlusion identified by transcranial Doppler predicts the response to intravenous thrombolysis for stroke. Stroke 2007;38:948-954.

-26 Rubiera M, Ribo M, Delgado-Mederos R, Santamarina E, Delgado P, Montaner J, Alvarez-Sabin J, Molina CA: Tandem internal carotid artery/middle cerebral artery occlusion: an independent predictor of poor outcome after systemic thrombolysis. Stroke 2006;37:2301-2305.

27 De Silva DA, Brekenfeld C, Ebinger M, Christensen S, Barber PA, Butcher KS, Levi CR, Parsons MW, Bladin CF, Donnan GA, Davis SM: The benefits of intravenous thrombolysis relate to the site of baseline arterial occlusion in the Echoplanar Imaging Thrombolytic Evaluation Trial (EPITHET). Stroke 2010;41:295-299.

28 Mokin M, Kass-Hout T, Kass-Hout O, Dumont TM, Kan P, Snyder KV, Hopkins LN, Siddiqui AH, Levy EI: Intravenous thrombolysis and endovascular therapy for acute ischemic stroke with internal carotid artery occlusion: a systematic review of clinical outcomes. Stroke 2012;43:2362-2368.

29 Kimura K, Aoki J, Sakamoto Y, Kobayashi K, Sakai K, Inoue T, Iguchi Y, Shibazaki K: Administration of edaravone, a free radical scavenger, during t-PA infusion can enhance early recanalization in acute stroke patients - a preliminary study. J Neurol Sci 2012;313:132-136.

-30 Koton S, Tanne D, Bornstein NM: Ischemic stroke on awakening: patients' characteristics, outcomes and potential for reperfusion therapy. Neuroepidemiology 2012;39:149-153.

-31 Serena J, Davalos A, Segura T, Mostacero E, Castillo J: Stroke on awakening: looking for a more rational management. Cerebrovasc Dis 2003;16:128-133.

32 Roveri L, La Gioia S, Ghidinelli C, Anzalone N, De Filippis C, Comi G: Wake-up stroke within 3 h of symptom awareness: imaging and clinical features compared to standard recombinant tissue plasminogen activator treated stroke. J Stroke Cerebrovasc Dis 2011, E-pub ahead of print.

33 Silva GS, Lima FO, Camargo EC, Smith WS, Singhal AB, Greer DM, Ay H, Lev MH, Harris GJ, Halpern EF, Sonni S, Koroshetz W, Furie KL: Wake-up stroke: clinical and neuroimaging characteristics. Cerebrovasc Dis 2010;29: 336-342.

-34 Todo K, Moriwaki H, Saito K, Tanaka M, Oe H, Naritomi H: Early CT findings in unknown-onset and wake-up strokes. Cerebrovasc Dis 2006;21:367-371.

-35 Campbell BC, Costello C, Christensen S, Ebinger M, Parsons MW, Desmond PM, Barber PA, Butcher KS, Levi CR, De Silva DA, Lansberg MG, Mlynash M, Olivot JM, Straka M, Bammer R, Albers GW, Donnan GA, Davis SM: Fluidattenuated inversion recovery hyperintensity in acute ischemic stroke may not predict hemorrhagic transformation. Cerebrovasc Dis 2011;32:401-405.

-36 Ebinger M, Ostwaldt AC, Galinovic I, Rozanski M, Brunecker P, Nolte CH, Endres M, Fiebach JB: Clinical and radiological courses do not differ between fluid-attenuated inversion recovery-positive and negative patients with stroke after thrombolysis. Stroke 2010;41:1823-1825.

-37 Petkova M, Rodrigo S, Lamy C, Oppenheim G, Touze E, Mas JL, Meder JF, Oppenheim C: MR imaging helps predict time from symptom onset in patients with acute stroke: implications for patients with unknown onset time. Radiology 2010;257:782-792.

-38 Calamante F, Lythgoe MF, Pell GS, Thomas DL, King MD, Busza AL, Sotak CH, Williams SR, Ordidge RJ, Gadian DG: Early changes in water diffusion, perfusion, T1, and T2 during focal cerebral ischemia in the rat studied at 8.5 T. Magn Reson Med 1999;41:479-485. 